\title{
Simulations of Turbine Cooling Flows Using a Multiblock-Multigrid Scheme
}

Erlendur Steinthorsson

Institute for Computational Mechanics in Propulsion

Cleveland, Ohio

Ali A. Ameri

AYT Corporation

Brook Park, Ohio

David L. Rigby

NYMA, Inc.

Brook Park, Ohio

October 1996

Prepared for

Lewis Research Center

Under Cooperative Agreement NCC3-370

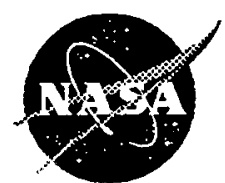

National Aeronautics and

Space Administration

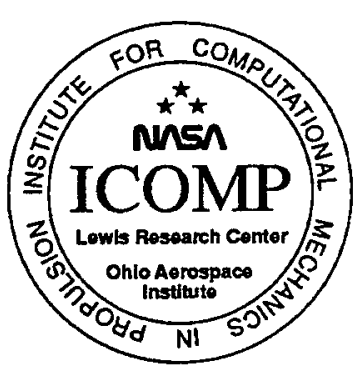




\title{
SIMULATIONS OF TURBINE COOLING FLOWS USING A MULTIBLOCK-MULTIGRID SCHEME
}

\author{
Erlendur Steinthorsson ${ }^{*}$ \\ Institute for Computational Mechanics in Propulsion, \\ NASA Lewis Research Center, Cleveland, Ohio \\ Ali A. Ameri \\ AYT Corporation, Brook Park, Ohio \\ and \\ David L. Rigby $\dagger^{\dagger}$ \\ NYMA, Inc, Brook Park, Ohio
}

\begin{abstract}
Results from numerical simulations of air flow and heat transfer in a "branched duct" geometry are presented. The geometry contains features, including pins and a partition, as are found in coolant passages of turbine blades. The simulations were performed using a multi-block structured grid system and a finite volume discretization of the governing equations (the compressible Navier-Stokes equations). The effects of turbulence on the mean flow and heat transfer were modeled using the Baldwin-Lomax turbulence model. The computed results are compared to experimental data. It was found that the extent of some regions of high heat transfer was somewhat under predicted. It is conjectured that the underlying reason is the local nature of the turbulence model which cannot account for upstream influence on the turbulence field. In general, however, the comparison with the experimental data is favorable.
\end{abstract}

\section{Introduction}

In modern gas turbine engines, the engine components under the highest thermal loads are cooled using air which is bled from the compressor stage of the engine. The cooling is needed to ensure the structural integrity of the engine components and to enhance durability. At the same, the air that is used for cooling does not contribute towards generation of useful work by the engine and, therefore, constitutes an extra load on the engine. Consequently the design of cooling schemes involves delivering sufficient cooling to entire components

\footnotetext{
*Senior Research Associate, Member AIAA

†Research Engineer, Member AIAA.
}

with minimum use of coolant air. Note, cooling of the high pressure stages of a gas turbine engine is particularly critical since the turbine blades are under high mechanical loads as well as a high thermal load. ${ }^{1}$

It is quite apparent that the better the tools for predicting and analyzing the performance of proposed cooling configurations, the faster a designer can arrive at an effective and reliable design. In particular, a tool for predicting details of heat transfer and temperature distributions allows the designer to pinpoint regions where the blade temperature is too high (insufficient cooling) or unnecessarily low (excessive cooling). However, in order to produce such predictions, threedimensional (3D) simulations of both the coolant flow and the "external" cascade flows in the engines must be performed. Such simulations can be done to a varying degree of fidelity using a number of numerical methods.

The objective of this research is to develop a capability to simulate in detail the three-dimensional flow and heat transfer in turbomachinery. A particular focus of the research is the analysis of coolant flow within internal passages of turbine blades. The approach pursued is to use semi-automatically generated (in the future, fully automatically generated) multi-block grid systems ${ }^{2}$ to model the complicated coolant-passage geometries, and to use finite volume methods (see e.g. Ref. 3) to discretize the equations governing the air flow and heat transfer. The advantages of this approach include the flexibility and computational efficiency of the finite volume method and the suitability of the block-structured body-fitted grid systems for detailed simulations of viscous internal flows. This approach is the basis behind a recently developed computer code, TRAF3D.MB, which is used for all computations presented in this paper. ${ }^{4}$

The ability to model the complicated geometries of coolant passages using a multi-block grid system was demonstrated in an earlier publication. ${ }^{5}$ In that study, 
a high-quality multi-block grid system was generated for a "branched duct" geometry (see Fig. 1) which was used in experiments at NASA Lewis Research Center. ${ }^{6}$ Preliminary results for the flow field within the passage were also reported. In this paper, simulations of the flow and heat transfer in the branched duct are pesented and compared to experimental data. These results were obtained using a Baldwin-Lomax turbulence model. 7,8

In the next section of this paper, the physical problem analyzed here and its origin are described, and the experimental data discussed. Afterwards, the numerical method of solution is described briefly. Then the results of computations are presented and compared to the experimental data. The paper concludes with a discussion about the present approach and its suitability for simulations of coolant passage flows.

\section{Description of Problem and Experimental Data}

As in a previous paper, ${ }^{5}$ the flow of air through a "branched duct" configuration (see Fig. 1) is simulated. This duct was used in experiments at NASA Lewis Research center as a part of an effort aimed at improving understanding of and predictive capability for coolant flows in turbomachinery. ${ }^{6}$ The duct was designed to include geometric features which are to be found in coolant passages of turbine blades, namely the sudden expansion, the partition and pins (note, pins are often included to exert control over the flow rather than to increase heat transfer although the latter may follow). In the experiments, the bottom wall was heated using Inconel heaters to emulate the thermal loading on a turbine blade. To obtain the heat transfer rates, the floor of the duct was painted with a liquid crystal paint calibrated to display yellow for temperatures on a narrow band around $37.8^{\circ} \mathrm{C}$. For a given power setting to the Inconel heaters and a fixed flow rate, a sharp yellow line would appear on the channel floor where the surface temperature was within that narrow band. By varying the power setting (heat flux), the location of the yellow line was made to shift, providing a map of the heat flux and wall temperature data for the entire test section. From this map, a heat transfer coefficient was computed.

The heat transfer coefficient was measured in this manner for three entrance Reynolds numbers (based on the hydraulic diameter of the inflow duct, the flow speed at the entrance section, and properties of air at room temperature). Figure 2 (reproduced from Ref. 6 with permission) shows a plot of the heat transfer coefficient, $h$, obtained in the experiments for entrance Reynolds number of 335,000 . The figure reveals that $\mathrm{h}$ lies between about $100 \mathrm{~W} / \mathrm{m}^{2} K$ and $350 \mathrm{~W} / \mathrm{m}^{2} \mathrm{~K}$. In the inlet duct, for instance, the heat transfer coeffcient is near $170 \mathrm{~W} / \mathrm{m}^{2} \mathrm{~K}$ initially but drops to below $140 \mathrm{~W} / \mathrm{m}^{2} \mathrm{~K}$ near the pins. In the shear layer off the expansion corner, $h$ varies sharply from about $100 \mathrm{~W} / \mathrm{m}^{2} K$ to above $150 \mathrm{~W} / \mathrm{m}^{2} \mathrm{~K}$. Towards the outflow region in the upper branch of the duct (above the partition), $h$ has a value of about $160 \mathrm{~W} / \mathrm{m}^{2} \mathrm{~K}$, whereas in the lower branch (behind the pins) its value drops to little above $100 \mathrm{~W} / \mathrm{m}^{2} \mathrm{~K}$. The highest values of the heat transfer coefficient are found above the partition and around the pins.

\section{Flow Solver}

The TRAF3D.MB code used in the present study is a general purpose flow solver for simulations of compressible viscous flows in complicated geometries. To handle the complicated geometries, the code has the capability to work with multi-block grid systems of arbitrary complexity, i.e., there is no restriction on the number of blocks or on how they are connected. However, the grid lines in the multi-block grid should, for accuracy, be at least $C^{1}$-continuous across block boundaries (except at singular points in the grid). The code also has a capability to handle discontinuous branch cuts within individual blocks.

The governing equations used in the code are the full three-dimensional, compressible Navier Stokes equations. The equations are discretized using a secondorder accurate in space, cell-centered finite volume discretization. In the present work, central differencing is used for computation of convective fluxes, along with mixed $2 n d$ and $4 t h$ difference artificial dissipation with the eigenvalue scaling of Martinelli and Jameson. ${ }^{9}$ Solutions are marched to steady state using a four-stage Runge Kutta scheme. Local time stepping, implicit residual smoothing and multigrid are used to accelerate convergence of the solutions to steady state. The code is described in essential details in Ref. 4.

In the simulations presented here, the BaldwinLomax turbulence model $1^{7,8,10}$ was used to account for the effects of turbulence on the mean flow. A very standard implementation of the model was used to compute the eddy viscosity in the neighborhood of a single noslip boundary (wall). However, to compute eddy viscosity in corners between adjacent walls, a square-ofdistance weighted averaged was used as described in Ref. 10.

\section{Results}

Numerical simulations of the air flow and heat transfer in the branched duct were done for a nomi- 
nal Reynolds number of 335,000 . In the simulations, the flow was assumed to be symmetric about the center plaxe of the duct, although in the experiments only one side of the duct was heated. To emulate the heating of the channel floor, the wall temperature was assumed to be $1.1 T_{0}$, where $T_{0}$ is the stagnation temperature of the incoming air (room temperature). All other solid walls were also assumed to be at a constant temperature of $1.1 T_{0}$. Non-slip boundary condition for velocity at all solid walls was used. At the inflow boundary, the incoming air was assumed to be parallel to the channel and at constant stagnation temperature $\left(T_{0}\right)$ and stagnation pressure $\left(P_{0}\right)$. At outflow boundaries, the average back pressure was specified for each out-flow branch $-0.9685 P_{0}$ for the upper branch and $0.9725 P_{0}$ for the lower branch-while the pressure profile was extrapolated from the interior. These values for back pressure were obtained from the experimental data. ${ }^{11}$ Other variables at the outflow boundary were extrapolated from the interior using first-order extrapolation.

The grid system used in the simulations is the same as that described in Ref. 5. This grid system. was generated using a commercially available grid generator, called GridPro/az3000. The three-dimensional grid system was formed by the stacking of two dimensional grids. The multi-block grid was generated in a total of 283 blocks and contains about 2 million cells. Grid points were clustered towards all solid walls. Typical grid spacing normal to side walls, pins and partition was $2 \cdot 10^{-4}$ whereas grid spacing at the channel floor was $1.1 \cdot 10^{-4}$ (note, dimensions are normalized by the height from the floor of the channel to the symmetry plane). The grid system is shown in Fig. 3. Note that the grid is smooth, nearly orthogonal everywhere, and at least $C^{1}$ continuous across all block boundaries. For further discussion and description of the grid system, see Ref. 5.

A heat transfer coefficient was computed from the numerical results in the same manner as described in Ref. 6 for the experimental results, i.e.,

$$
h=\frac{Q / A}{T_{w}-T_{R}}
$$

where $T_{w}$ is the specified wall temperature (measured in the experiments) and $T_{R}$ is a recovery temperature of the entrance flow. $T_{R}$ is defined as

$$
T_{R}=T_{s}+r\left(T_{0}-T_{s}\right) ; \quad r=(P r)^{1 / 3}
$$

where $T_{s}$ is the static temperature at the inflow and $P r$ is the Prantl number. The heat flux, $Q / A$, is computed from the numerical solution based on temperature gradient at the wall.

With the boundary conditions and grid system as described above, the simulations were carried out. Post-processing of the numerical solution revealed that the actual Reynolds number obtained (based on hydraulic diameter and center line inflow velocity) was about 380,000 , compared to the nominal value of 335,000 for the experiments. When the computations were halted, the residual for the continuity equation residual had dropped between four and five orders of magnitude and mass balance (difference between inflow and outflow) was negligible.

The results from the simulation are shown in Fig. 4-8. Figure $4 a$ shows the velocity field in the symmetry plane of the duct (only every other grid point in each direction is plotted). As expected, the figure reveals a massive separation off the expansion corner in the duct. The figure also reveals the turning of the flow approaching the pins toward the upper branch of the duct, caused by the resistance to the flow provided by the array of pins in the lower branch. This turning causes the flow to approach the partition at an angle of attack, which in turn causes the flow to separate above the partition. A close look reveals that the main separation above the partition starts slightly down stream of the rounded edge of the partition (a small separation is also found on the rounded edge where strong adverse pressure gradient prevails). While hard to judge without a more detailed analysis than afforded here, it is believed that this occurs due to the influence of secondary flows in the upper channel. Figures $4 \mathrm{~b}$ and $4 \mathrm{c}$ show the behavior of the flow near the floor of the channel. Figure $4 \mathrm{~b}$ shows limiting stream lines (tangent to shear-stress lines) on the channel flow for the center region of the duct. This figure shows well the separated flow in the corner and the existence of a saddle point near the upper side wall where flow diverted from the main stream impacts on the floor. Figure $4 \mathrm{c}$ shows in more detail the flow pattern near the leading edge of the partition, illustrating the complexity of the flow due to the presence of the pins and partition.

The heat transfer results, which are the main objective of this paper, are shown in Fig. 6. Figure 6a shows most of the test section while Fig. $6 \mathrm{~b}$, shows a close-up view of the heat transfer around the pins and partition. The contour levels plotted in the figures are the same as those plotted in Fig. 2. Comparison of Fig. 2a and Fig. 6a reveals that the general features of the heat-transfer map are similar, although the numerical simulation tends to under predict the extent of regions with a high heat transfer rate. This is true in particular 
behind the pins and immediately above the partition. However, in the inflow duct, in the shear layer off the expansion corner, and in the down-stream sections of the outflow branches, the values are very comparable. Note, the grid spacing near the floor of the channel was small, corresponding to $y+$ of about 0.2 to 0.6 . A closeup view of the region around the array of pins reveals that immediately in front of the pins, the heat transfer is well predicted, with both values and location of contours well matched. However, the high heat transfer that was obtained in the experiments for the wake regions behind the pins is not captured in the computations.

Although it can be said that the predictions of heat transfer were fairly successful, it is likely that an improved modeling of the effects of turbulence will bring improved predictions of the flow and heat transfer. From the results presented here, it appears that heat transfer is in general well predicted at locations where no significant "events" have occurred in the flow, while in other regions it is under predicted. For instance, in the inflow duct, the values of the heat transfer coefficient is well predicted, as well as in the shear layer off the expansion corner. Similarly, immediately in front of the pins the heat transfer is well predicted, as the fluid that impinges on the channel floor has passed through the boundary layer on the pins, where turbulent fluctuations have been dampened out. In contrast, in the wakes behind the pins, in the lower branch down stream of the pin array, and in the region above the partition, all regions where turbulence intensity in the flow may be affected by up-stream event in the flow, the heat transfer is under predicted. This is directly attributable to the nature of the Baldwin-Lomax turbulence model, which can only account for "local" effects but cannot account for the history of the flow.

\section{Conclusions}

In the present work, a methodology based on structured multi-block grid systems and finite-volume discretization techniques was used for simulating the flow of air through a complicated coolant passage configuration, namely the branched duct geometry of Fig.1. In general, the methodology worked well-a high quality multi-block grid system was generated for the complicated geometry without sacrificing continuity of the grid across blocks or grid structure, and a numerical solution for the flow in the duct was obtained which compared well to available experimental data. However, some remarks about the present methodology are in order.
In the current application, a large number of grid blocks-a total of 283-was used to model the geometry. This large number of blocks is a natural consequence of the procedure used to generate the grid. Many of the blocks were small. The block structure produced by the grid generator was used unmodified in the flow solver-i.e., no merging of blocks was done. This proved to be detrimental in two ways. On one hand, the large number of small blocks resulted in poor computational efficiency of the flow solver on vector supercomputers. On the other hand, implicit residual smoothing as implemented here, with no special treatment for cells adjacent to block boundaries, appeared to have a detrimental effect on the convergence. This happened as follows: The implicit residual smoothing is applied within each block, independent of all other blocks. The smoothing operator requires a boundary condition for the smoothed residual, which here was taken to be zero in the ghost cells. This is a typical approach which works reasonably well near physical boundaries. However, in the present application, this apparently resulted in slow convergence in regions where block boundaries intersected solid wall boundaries. This suggests that improvement in the implicit residual smoothing algorithm is needed. Excluding the effect of small blocks on the floating point performance of the code and the shortcoming of the present implementation of the implicit residual smoothing, the large number of blocks did not appear to significantly affect the performance of the algorithm. The reason, it is conjectured, is the strong coupling between blocks due to the implementation of the multigrid convergence acceleration and the explicit nature of the relaxation scheme (note, in the present implementation, all blocks-are coupled on every level of multigrid, and communication of data between blocks takes place only after the last stage of the Runge-Kutta scheme). The floating point efficiency of the code on vector computers can be enhanced by special programming practices. A more attractive approach is, however, to merge small blocks into larger ones that allow effective vectorization. This can be accomplished automatically using newly developed tools and algorithms (see e.g., Ref. 12).

Although conceptually simple, the Baldwin- Lomax turbulence model used in the simulations reported here often performs admirably. In fact, even for the case presented here, with obstructions in the flow field that cause massive changes in the flow, the model performed surprisingly well. However, it is clear that better predictions of heat transfer are desirable so that the numerical simulations truly be relied upon for design work where heat transfer is of importance. The current re- 
sults suggest that a turbulence model that can account for history effects is needed. Such model has already been implemented in the current flow solver but results are not available for the present case at this time.

\section{References}

1 Simoneau, R. J., and Simon, F. F., "Progress Towards Understanding and Predicting Heat Transfer in the Turbine Gas Path," Int. J. Heat and Fluid Flow, Vol. 14, No. 2, June 1993.

2 Surface Modeling, Grid Generation, and Related Issues in Computational Fluid Dynamic (CFD) Solutions, proceedings of a workshop held at NASA Lewis Research Center, May 9-11, 1995. NASA Conference Publication 3291.

3 Hirsch, C., Numerical Computation of Internal and External Flows, Vol. 2., John Wiley and Sons, Chichester, England, 1990.

4 Steinthorsson, E., Liou, M.-S., and Povinelli, L.A., "Development of an Explicit Multiblock / Multigrid Flow Solver for Viscous Flows in Complex Geometries," AIAA-93-2380, 1993. Also; NASA TM 106356 and ICOMP 93-34.

5 Steinthorson, E. and Ameri, A. A., "Computations of Viscous Flows in Complex Geometries Using Multiblock Grid Systems," AIAA-95-0177.
6 Russel, L.M., Hippensteele, S.A., Poinsatte, P.E., Thurman, D.R., and Simonyi, P.S., "Measurements and Computational Analysis of Heat Transfer and Flow in a Simulated Turbine Blade Internal Cooling Passage," AIAA-93-1797, 1993. Also; NASA TM 106189.

7 Baldwin, B. S. and Lomax, H., "Thin Layer Approximation and Algebraic Model for Separated Turbulent Flows," AIAA-78-257, 1978.

8 Chima, R. V., Giel, P. W., and Boyle, R. J., "An Algebraic Turbulence Model for Three-Dimensional Viscous Flows," NASA TM 105931.

9 Martinelli, L. and Jameson, A., "Validation of a Multigrid Method for the Reynolds Averaged Equations," AIAA-88-0414, 1988.

10 Arnone, A., Liou, M.-S., and Povinelli, L. A., "Multigrid Calculation of Three-Dimensional Viscous Cascade Flows," AIAA-91-3238, Sept. 1991.

11 Thurman, D.R., Vehicle Propulsion Directorate, U.S. Army Research Laboratory, NASA Lewis Research Center - personal communication.

12 Dannenhoffer III, J.D., "A Technique for Optimizing Grid Blocks," Proceedings, Surface Modeling, Grid Generation, and Related Issues in Computational Fluid Dynamic (CFD) Solutions, NASA Conference Publication 3291, pp. 751-762., May 1995. 


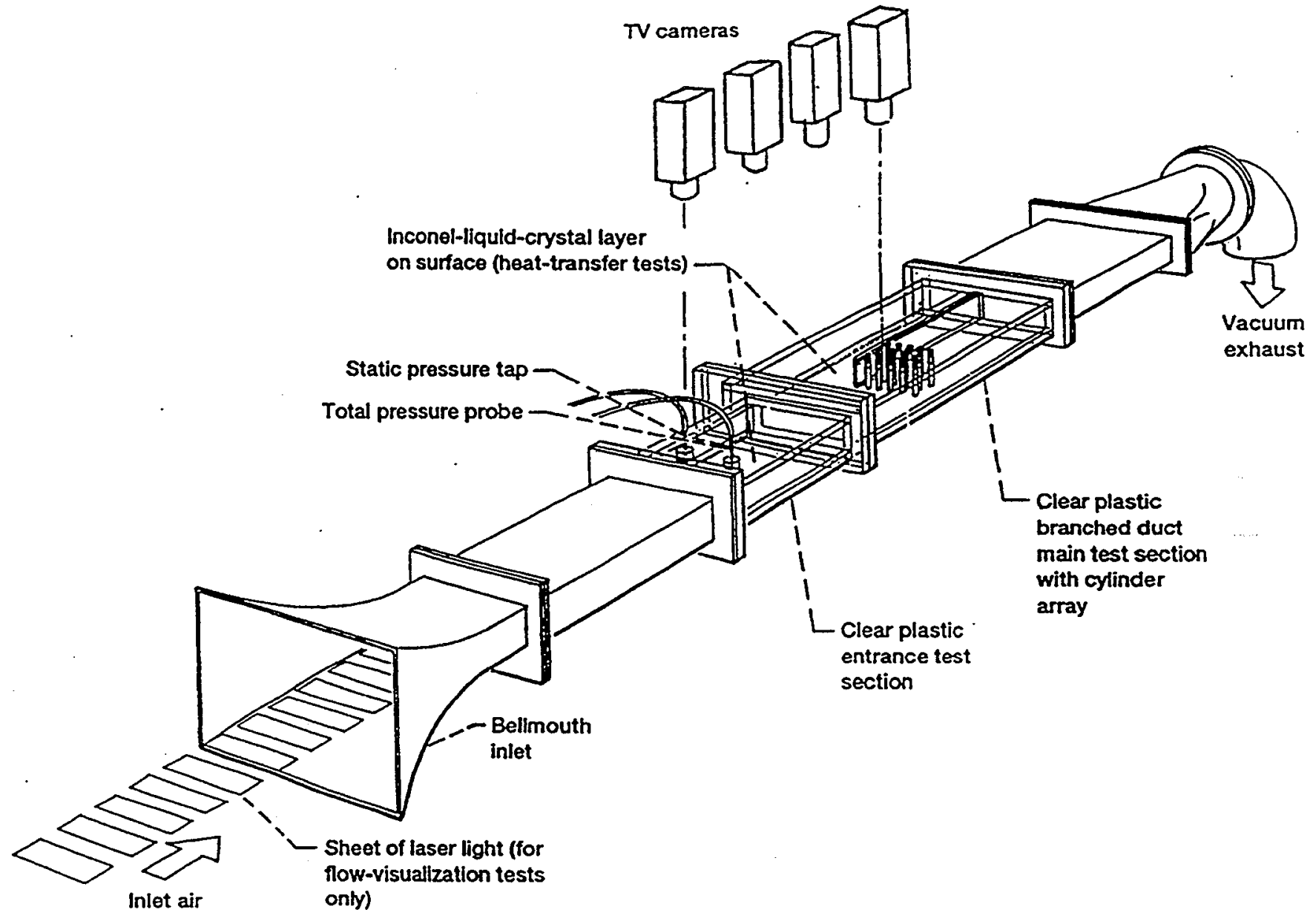

(a)

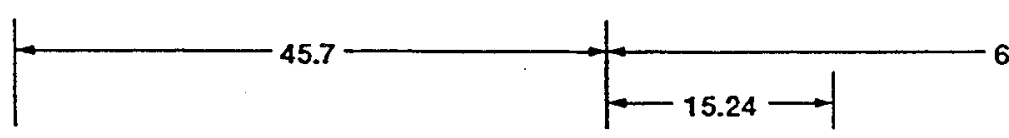

61.0

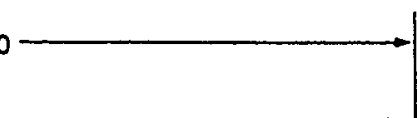

Note: Passage helght is 5.08

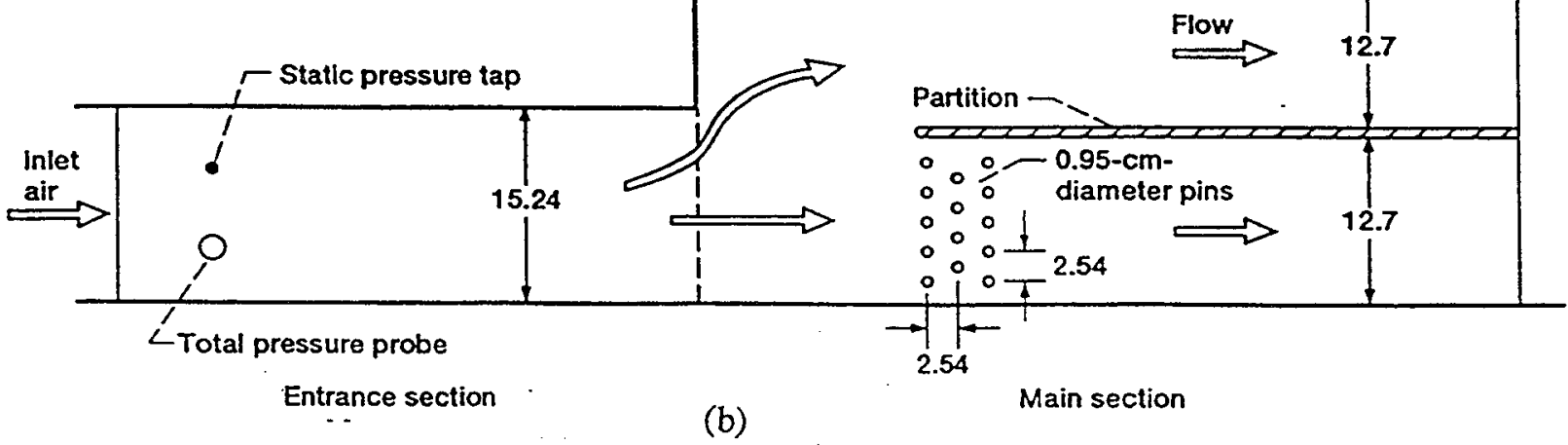

Figure 1: Branched duct geometry (a) experimental setup, (b) schematic drawing of the test section (all dimensions are in centimeters). Figure reprinted from Ref. 6 (with permission). 


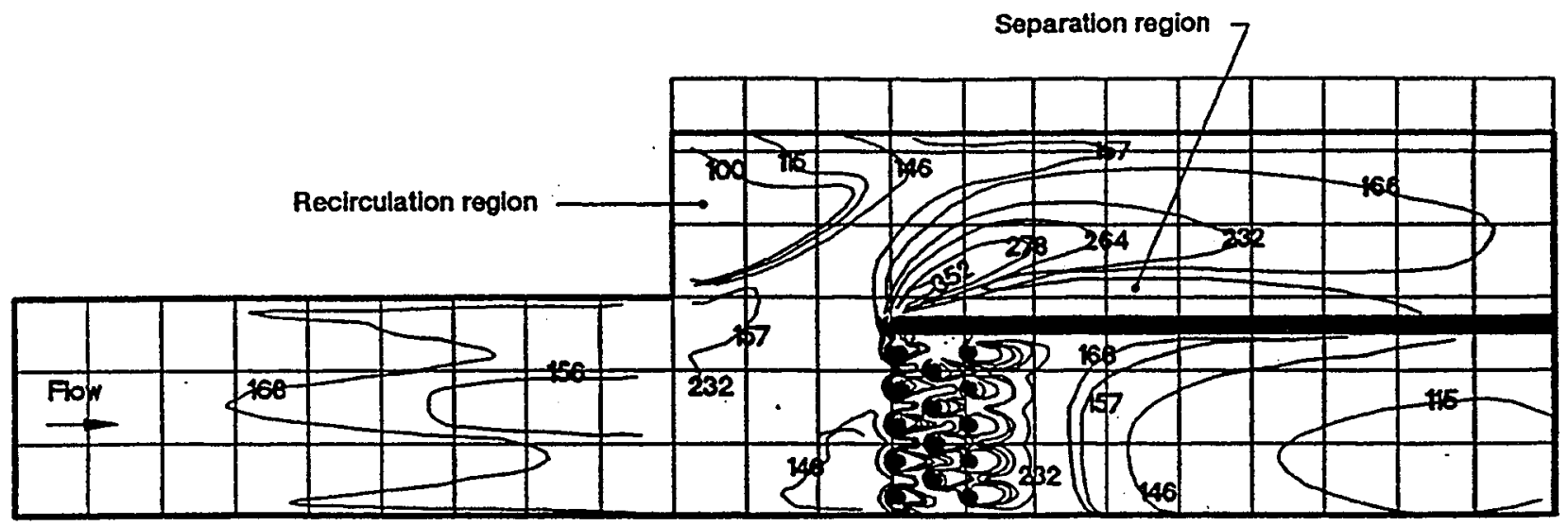

(a) Entire test surface.

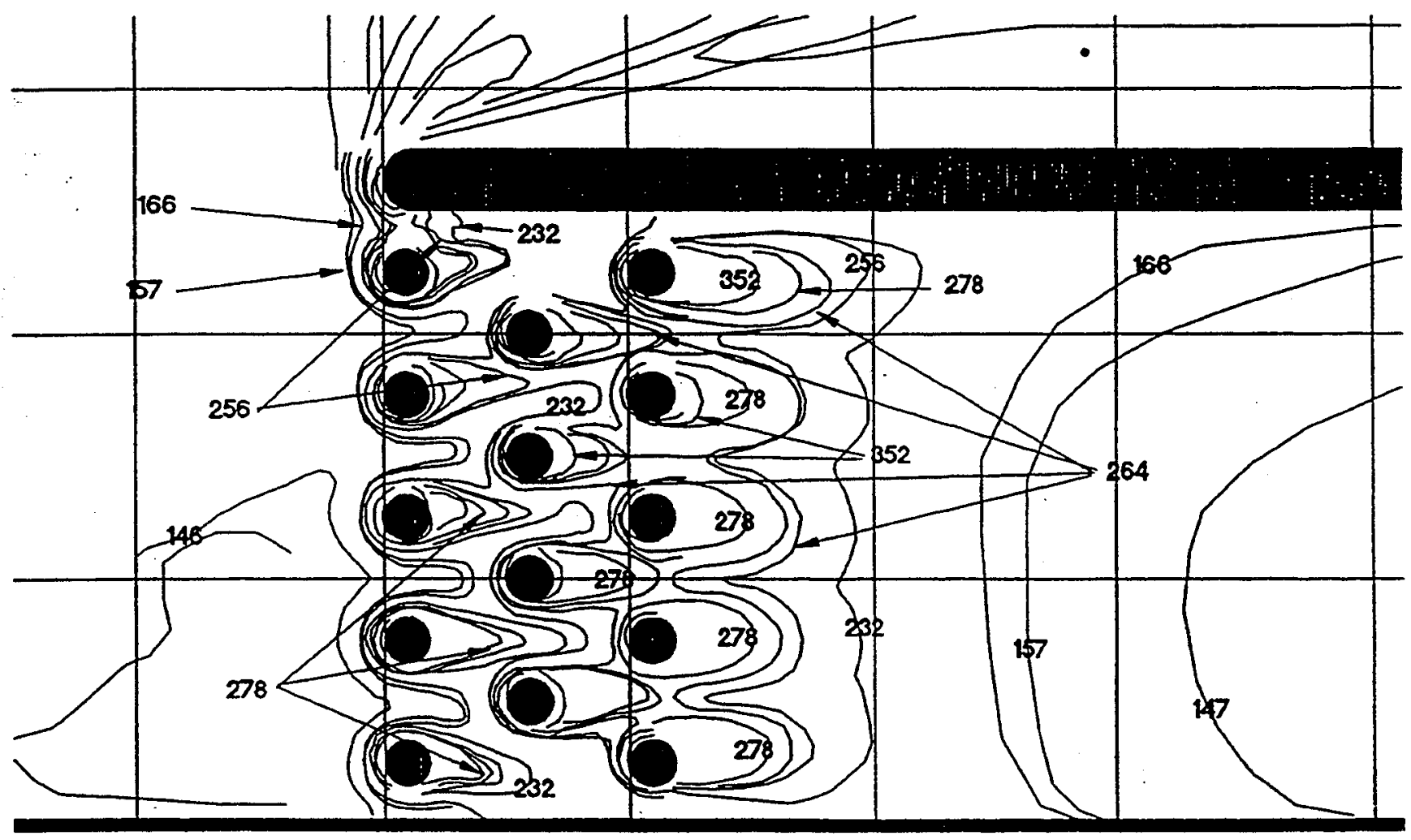

(b) Close-up of pin area.

Figure 2: Experimental heat transfer coefficient; Reynolds number, 335,000 (coefficients given in $W / m^{2} K$ ). Figure reprinted from Ref. 6 (with permission). 

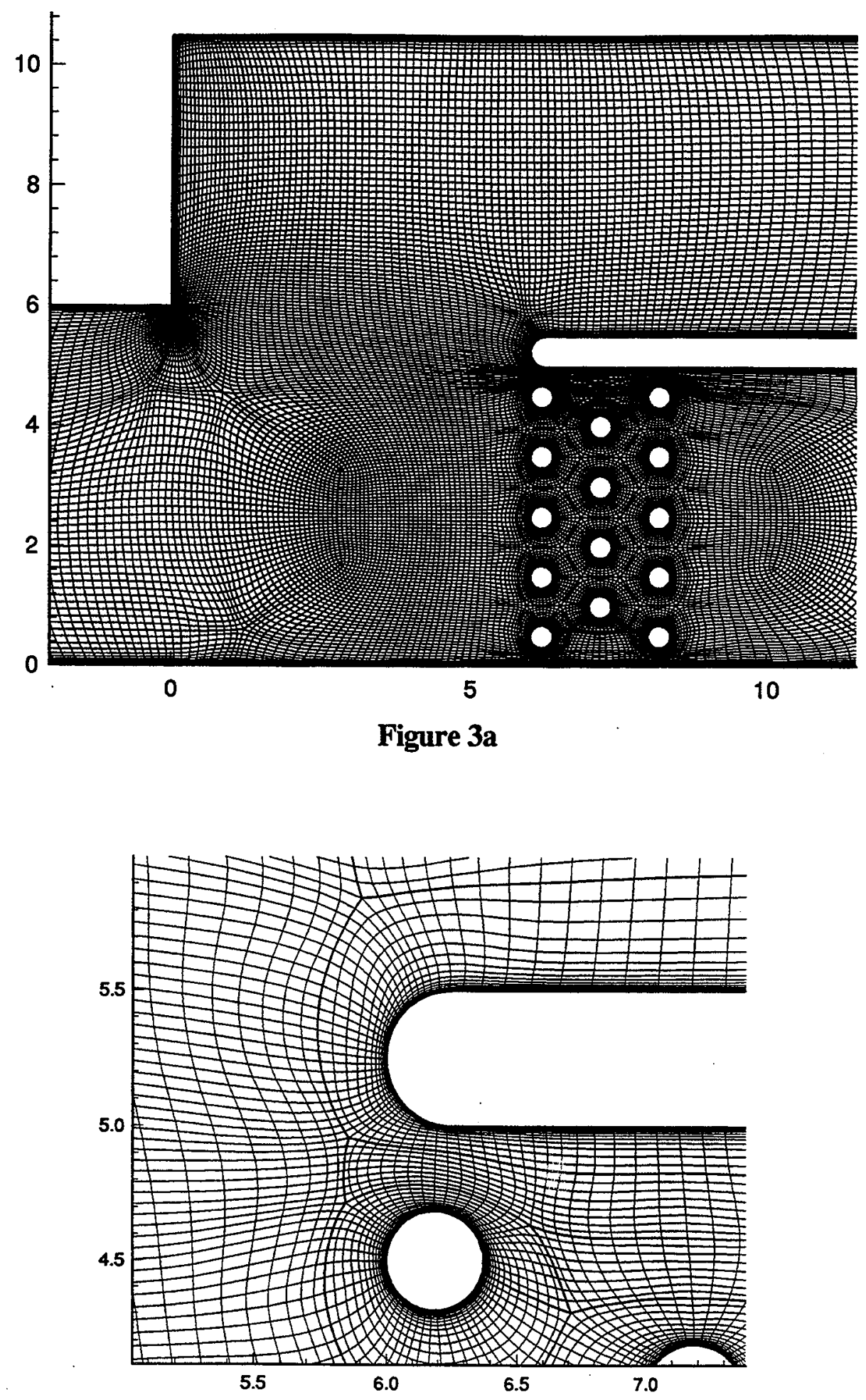

Figure 3b

Figure 3 (Continued on the next page). 


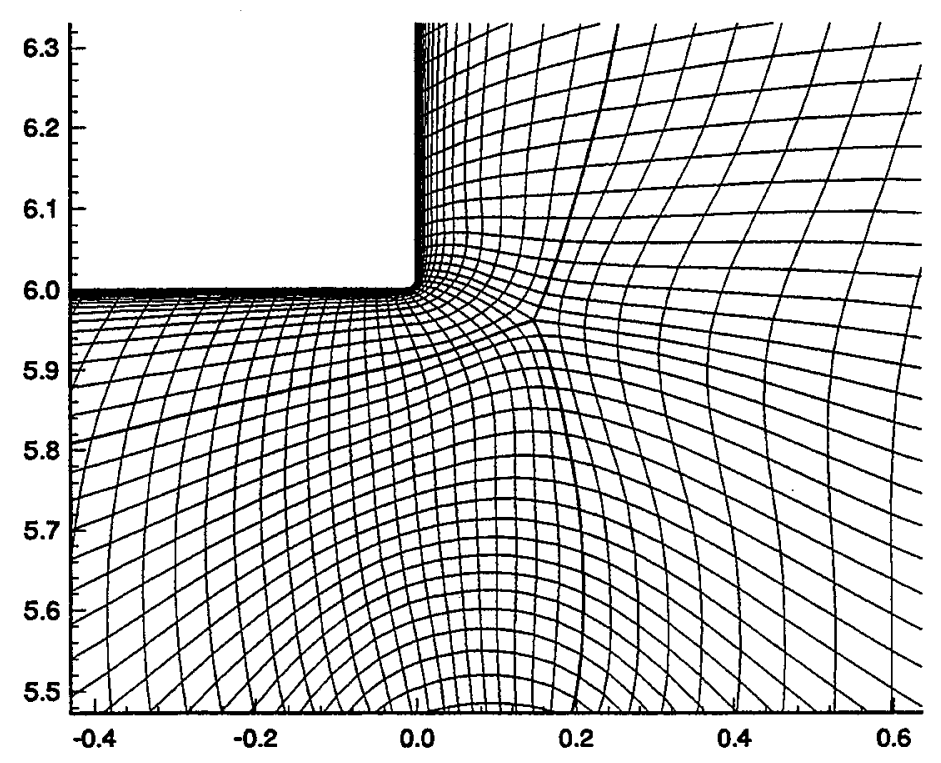

Figure 3c

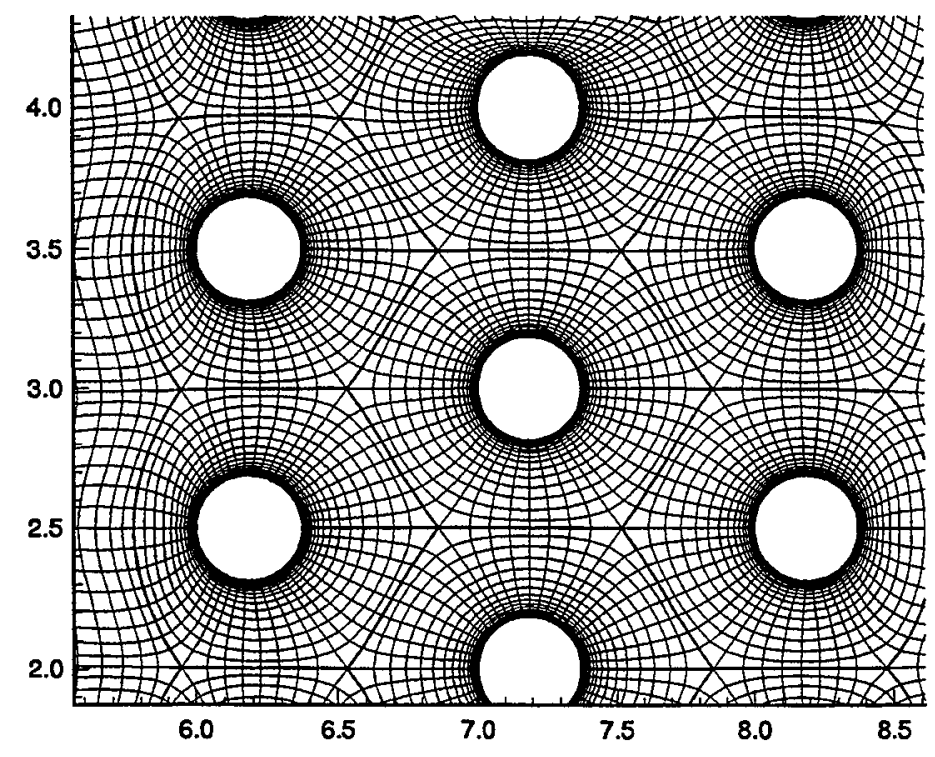

Figure 3d

Figure 3:Multiblock grid system for branched duct.

(a) Center region of duct.

(b) Leading egde of partition

(c) Expansion corner (slightly rounded)

(d) Array of pin fins. 

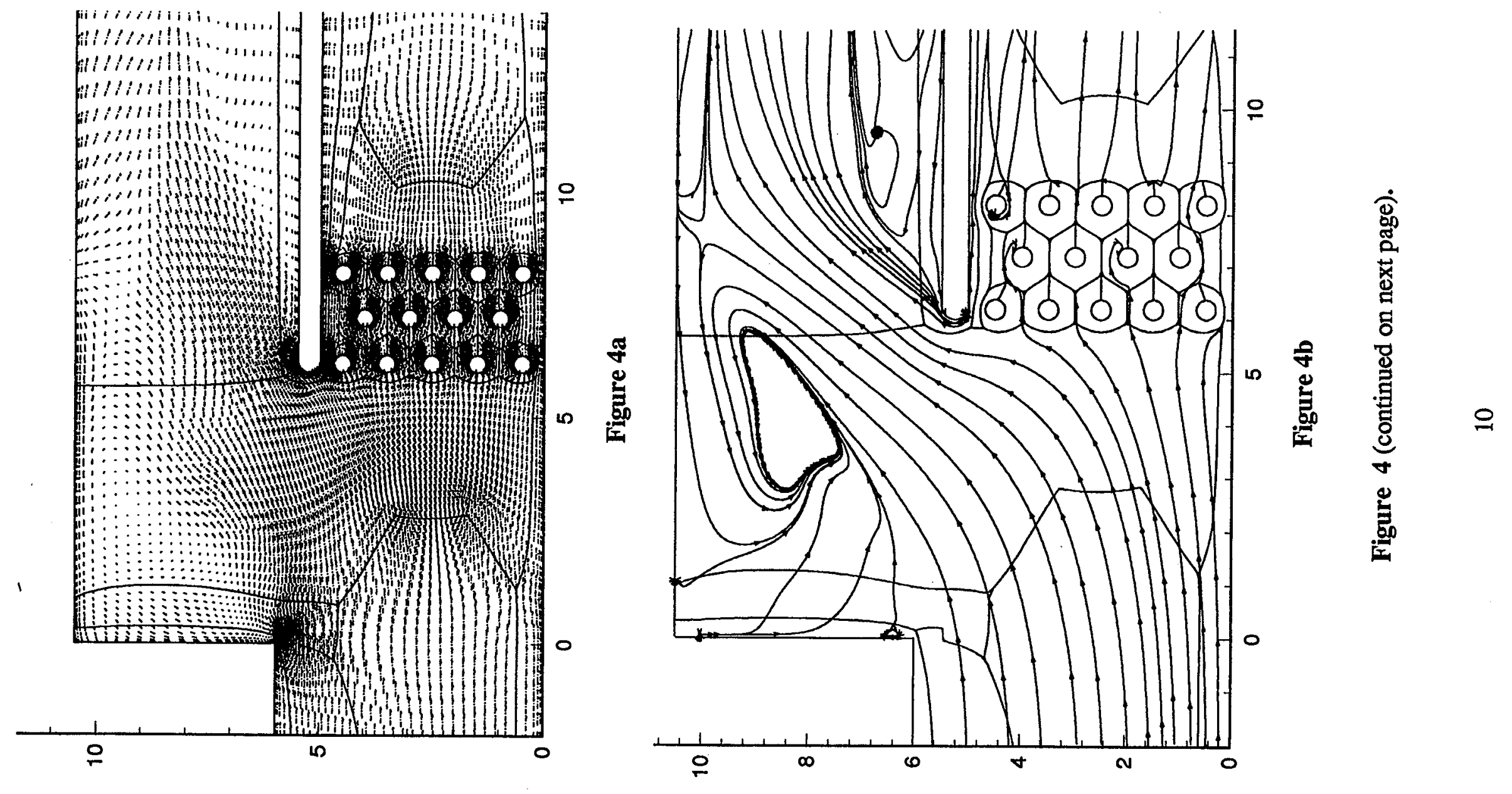


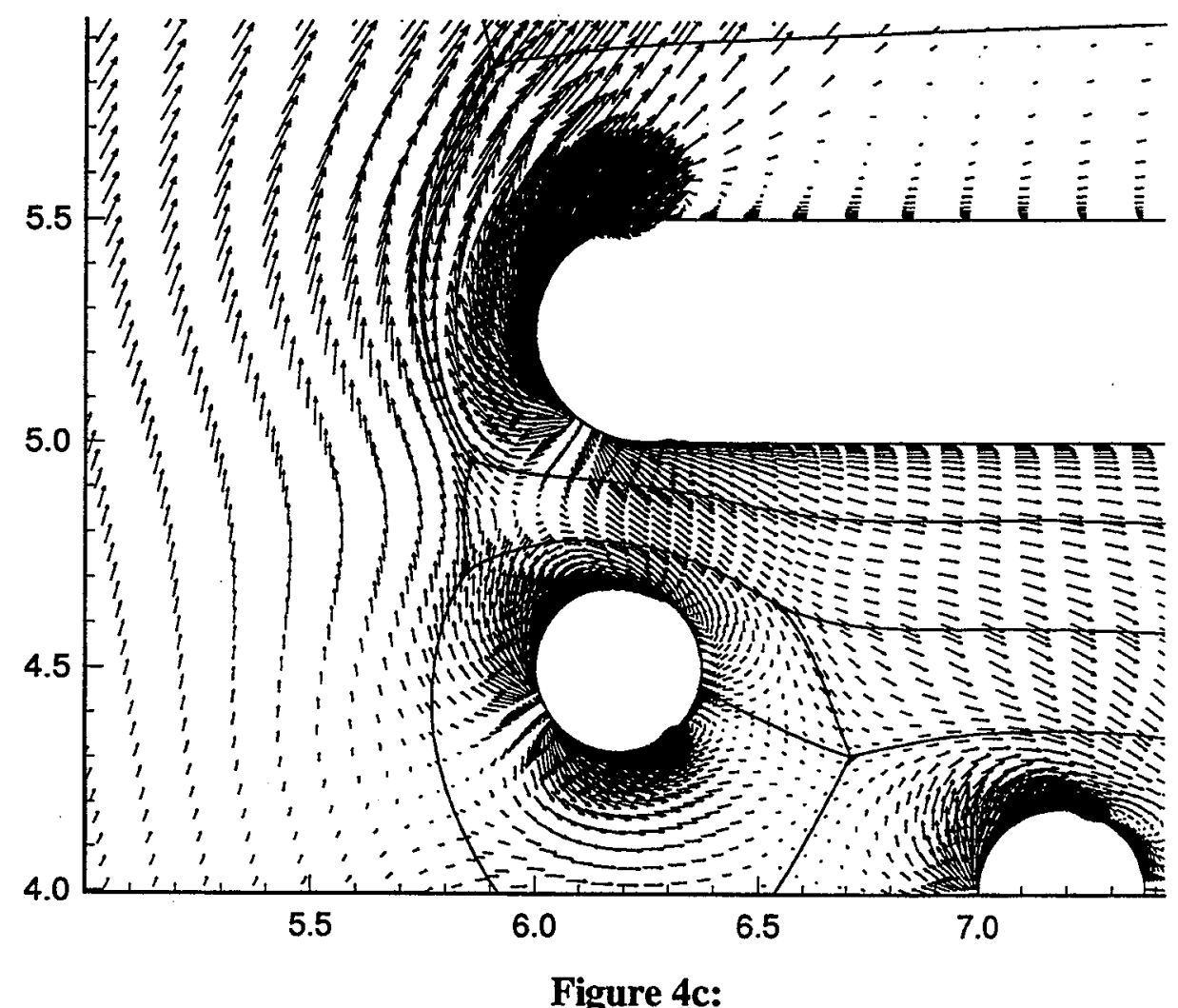

Figure 4: Flow field in branched duct.

(a) Velocity field in center region of duct (refernce vector has magnitude $\sqrt{R T_{0}}$

(b) Limiting streamline on channel floor (streams are tangent to shear stress on the floor)

(c) Shear stress direction on channel floor near leading edge of partition. 


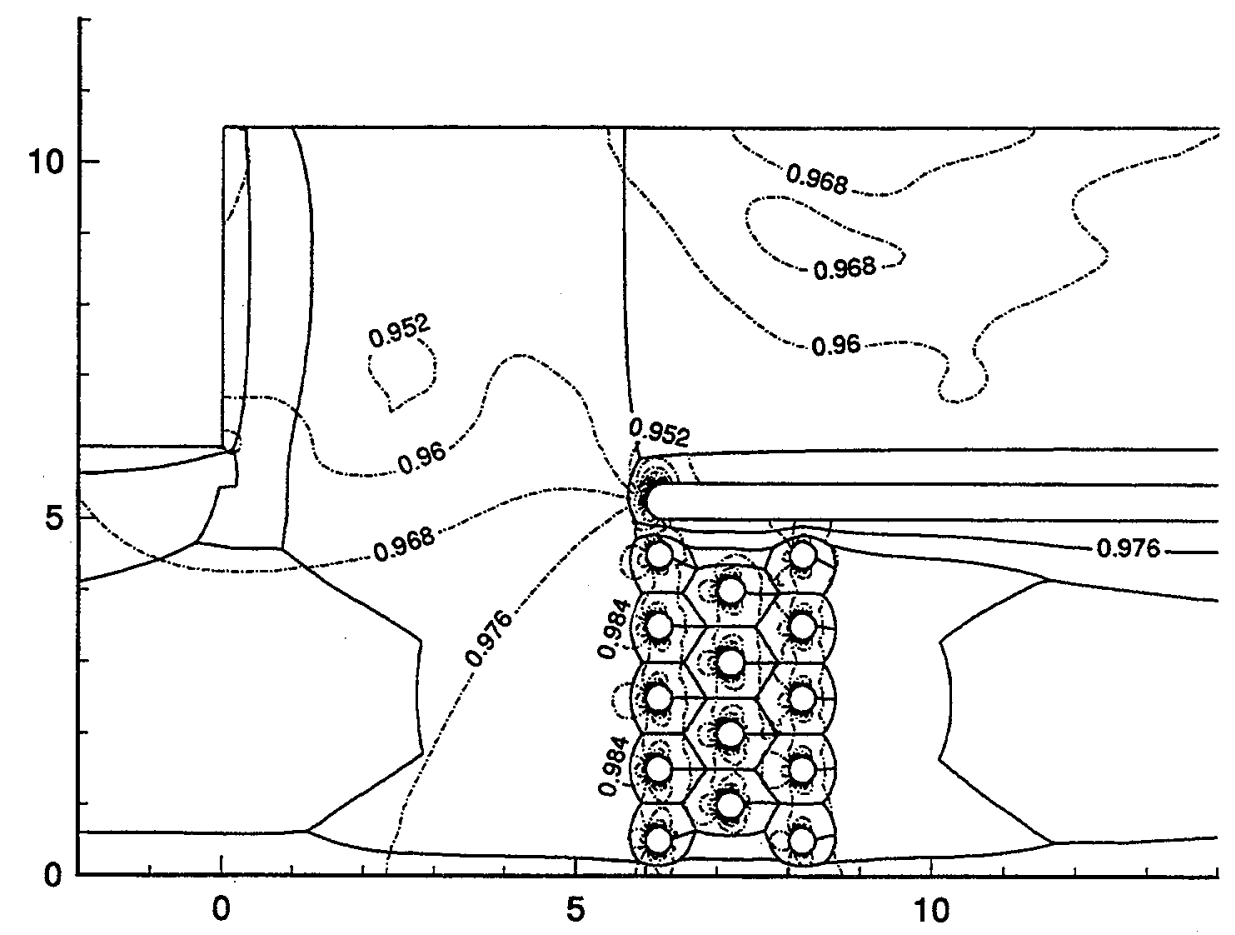

Figure 5: Static pressure $\left(\mathrm{P} / \mathrm{P}_{0}\right)$ in the symmetry plane of the duct.

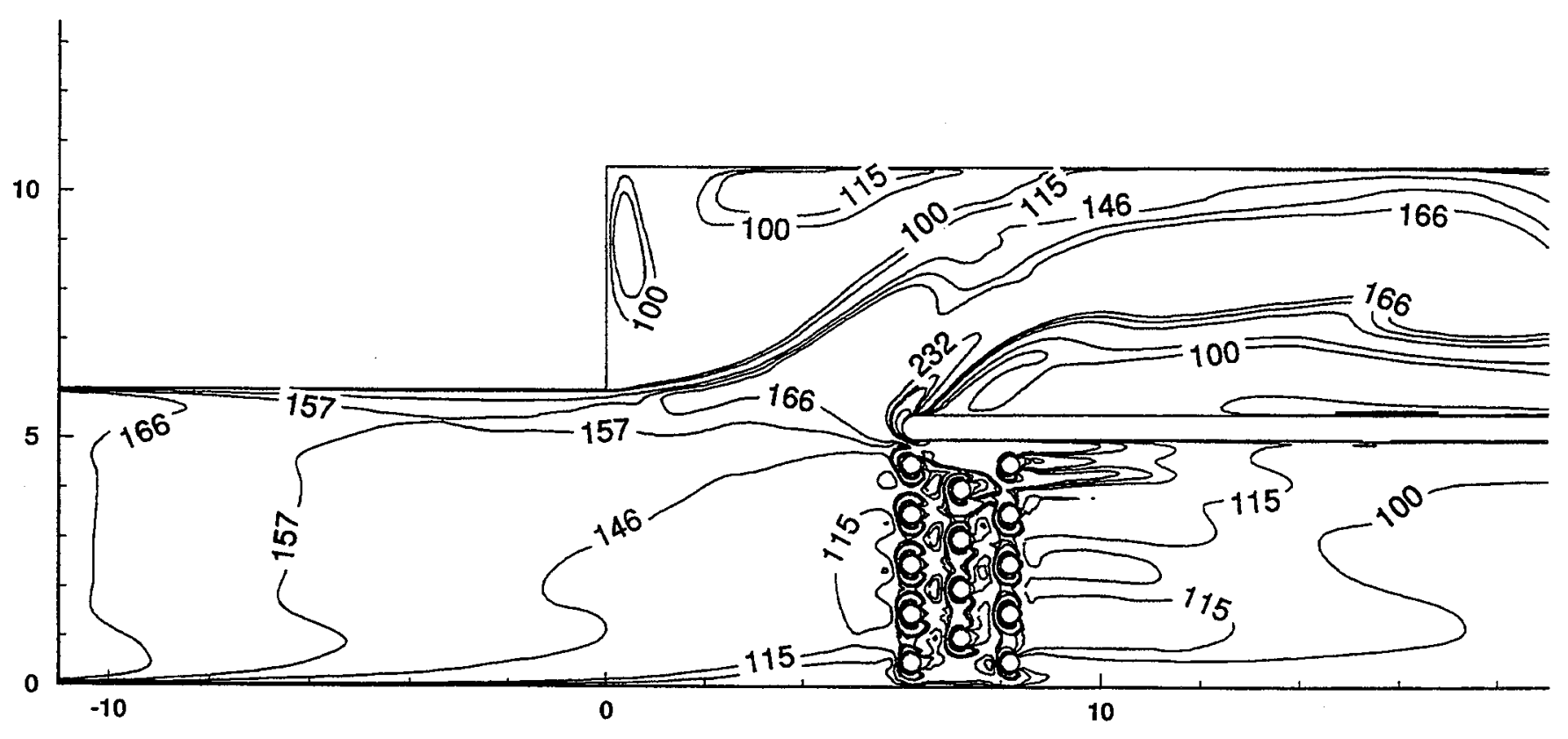

Figure 6a

Figure 6 (continued on next page). 


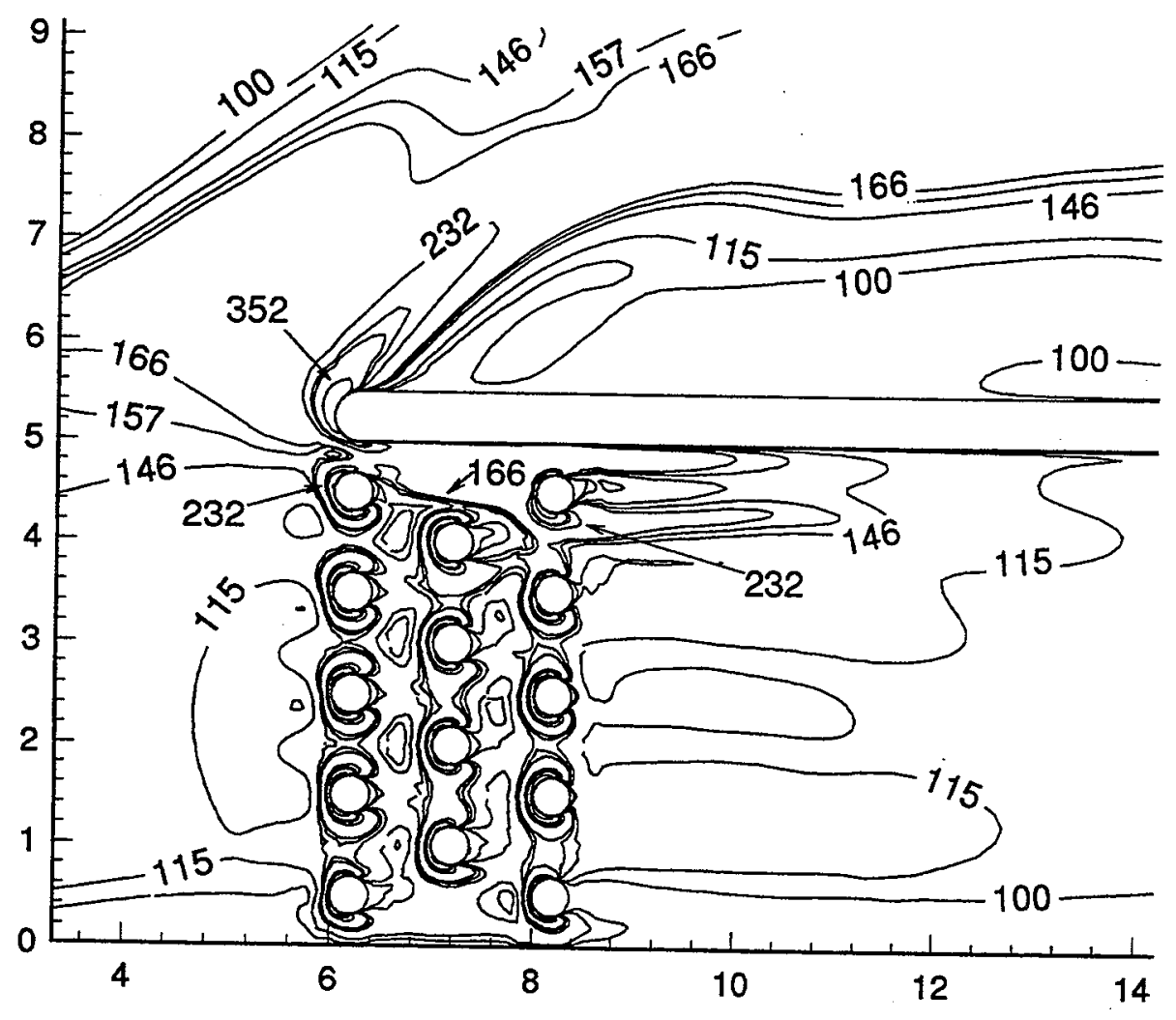

Figure 6b

Figure 6: Heat transfer coefficient on channel floor (W/mK ).

(a): Overall view of the duct.

(b): Close up view of pin array. 
Public reporting burden for this collection of information is estimated to average 1 hour per response, including the time for reviewing instructions, searching existing data sources, gathering and maintaining the data needed, and completing and reviewing the collection of information. Send comments regarding this burden estimale or any olher aspect of this Davis Highway, Sulte 1204, Arlington, VA 22202-4302, and to the Otfice of Management and Budget, Paperwork Reduction Project (0704-0183), Washington, DC 20503.

\begin{tabular}{|l|c|c|}
\hline 1. AGENCY USE ONLY (Leave blank) & $\begin{array}{c}\text { 2. REPORT DATE } \\
\text { October } 1996\end{array}$ & $\begin{array}{l}\text { 3. REPORT TYPE AND DATES COVERED } \\
\text { Contractor Report }\end{array}$
\end{tabular}

4. TITLE AND SUBTITLE

5. FUNDING NUMBERS

Simulations of Turbine Cooling Flows Using a Multiblock-Multigrid Scheme

6. AUTHOR(S)

WU-505-90-5K

NCC3-370

Erlendur Steinthorsson, Ali A. Ameri, and David L. Rigby

7. PERFORMING ORGANIZATION NAME(S) AND ADDRESS(ES)

8. PERFORMING ORGANIZATION REPORT NUMBER

Institute for Computational Mechanics in Propulsion

22800 Cedar Point Road

E-10488

Cleveland, Ohio 44142

9. SPONSORING/MONITORING AGENCY NAME(S) AND ADDRESS(ES)

National Aeronautics and Space Administration

Lewis Research Center

Cleveland, Ohio 44135-3191

10. SPONSORINGMONITORING

AGENCY REPORT NUMBER

NASA CR-198539

ICOMP-96-7

AIAA-96-0621

\section{SUPPLEMENTARY NOTES}

Prepared for the 34th Aerospace Sciences Meeting and Exhibit sponsored by the American Institute of Aeronautics and Astronautics, Reno, Nevada, January 15-18, 1996. Erlendur Steinthorsson, Institute for Computational Mechanics in Propulsion, NASA Lewis Research Center (work funded under NASA Cooperative Agreement NCC3-370); Ali A. Ameri, AYT Corporation, Brook Park, Ohio; and David L. Rigby, NYMA, Inc., 2001 Aerospace Parkway, Brook Park, Ohio 44142 (work funded under NASA Contract NAS3-27186). ICOMP Program Director, Louis A. Povinelli, organization code 2600 , (216) 433-5818.

12a. DISTRIBUTIONAVAILABILITY STATEMENT

12b. DISTRIBUTION CODE

Unclassified -Unlimited

Subject Category 34

This publication is available from the NASA Center for AeroSpace Information, (301) 621-0390.

13. ABSTRACT (Maximum 200 words)

Results from numerical simulations of air flow and heat transfer in a "branched duct" geometry are presented. The geometry contains features, including pins and a partition, as are found in coolant passages of turbine blades. The simulations were performed using a multi-block structured grid system and a finite volume discretization of the governing equations (the compressible Navier-Stokes equations). The effects of turbulence on the mean flow and heat transfer were modeled using the Baldwin-Lomax turbulence model. The computed results are compared to experimental data. It was found that the extent of some regions of high heat transfer was somewhat under predicted. It is conjectured that the underlying reason is the local nature of the turbulence model which cannot account for upstream influence on the turbulence field. In general, however, the comparison with the experimental data is favorable.

14. SUBJECT TERMS

Computational fluid dynamics; Turbine cooling; Multigrid; Multiblock grids 15. NUMBER OF PAGES 15

SECURTY CLASSIFICATION 18 , SECURTY CLASSIFICATION OF REPORT Unclassified OF THIS PAGE Unclassified

19. SECURITY CLASSIFICATION OF ABSTRACT Unclassified 